\title{
Do Upper Primary Mathematics Teachers Recognise Creativity Experience in their students?
}

\author{
Karen K L Hor
}

\begin{abstract}
The aim of this article is to explore if Singapore mathematics teachers recognize the creativity experience of upper primary school children when they attempted open-ended mathematics questions. These 17 students from Singapore Primary Schools (aged between 11 and 12 years old) attempted three different types of open-ended mathematics questions using pen-and-paper method. Their creativity experience was elicited via face-to-face interviews, and phenomenographic analysis surfaced three different ways of experiencing openness in learning: being assessed, making decisions and exploring with freedom. The students' written answers were graded by two experienced mathematics teachers. The analysis of the Teachers' Consensual Assessment (TCA) of open-ended mathematics answers seemed to indicate that students' creativity experience was seldom noticed or recognized by the Singapore primary mathematics teachers.
\end{abstract}

Keywords - creativity, open-ended mathematics questions, voices of children, education

\section{Introduction}

In the study of creativity in children, most researchers asked the adult caregivers of children about the children's creativity (see Antonietti, 2000; Cheng 2010). The children's thoughts on their creativity experience rarely came directly from them. This research thus first surfaced the children's experience via face-to-face interviews immediately after they had completed three different types of open-ended questions. Through phenomenographic analysis, the voices of these children were heard and three different ways of creativity experience emerged. Two experienced primary school mathematics teachers marked and graded these young participants' open-ended mathematics questions. Their consensual assessments seemed to indicate that they did not recognize and appreciate the creativity experience of those who were exploring with freedom while they experienced the phenomenon of open-ended mathematics questions.

\section{Background}

\section{A. The context of the study}

The phenomenon of this study was openness to experience in the domain of mathematics. Openness to experience here is referred from Rogers's (1961) theory of creativity for openness to experience. Therefore, the three types of open- ended mathematics questions in this study became the phenomenon experienced by the participants. The experience is considered as creative because open-ended tasks have been found to foster creativity in the work place (Amabile, 1982). In this case, the open-ended mathematics questions are also new to the participants because Singapore primary school children are usually well-trained in closed mathematics questions because of the high-stakes national assessment known as the Primary School Leaving Examination (PSLE). Therefore, the creativity experience of these children are new and in mathematics context, and they share their experience verbally in one-to-one interviews while attempting such written questions. Creativity experiences of children consisted of the generations of products and ideas that are novel and appropriate (Hennessey \& Amabile, 2010). Their experiences also have continuity and thus still have growth in their learning (Dewey, 1938).

This study uses the voices of children to record their qualitatively different ways in creativity experience. Children's voices are justified in research as it has the support from the United Nations Convention on the Rights of the Child or UNCRC (United Nations General Assembly, 1989)

article 12. This means that the United Nations General Assembly recognises children's views in matters relating to their lives because they have the right to be considered as persons and are active citizens in their societies.

Through phenomenographic analysis, the participants' voices expressed three different qualitatively different ways of experiencing creativity experience. All the participants expressed all the ways of creativity experience, but some expressed one way of creativity experience more than the other two.

This paper will discuss what the Teachers' Consensual Assessment (TCA) shows when teachers look at the answers of the participants who seem to express more of the third way of creativity experience, that is, those who expressed their creativity experience as one that they explored with freedom.

Karen Kar Lin Hor

Singapore University of Social Sciences Singapore 


\section{B. Three ways of experiencing creativity experience}

Phenomenography is a qualitative research approach to examine and investigate "the qualitatively different ways in which people experience, conceptualize, perceive, and understand various aspects of, and phenomena in, the world around them" (Marton, 1986, p.31). The two knowledge interests in phenomenography are the revelation of various human experience and awareness; and the provision of experiential descriptions of the variation (Marton \& Booth, 1997). Phenomenography's two main tenets are non-dualistic stance and the second-order perspective or "insider view" (Marton, 1981; Marton \& Booth, 1997). This research approach thus supports this researcher's aim of using voices of children to show that they are able to express their own experience in all aspects of their lives.

In this study's first conception, or way of experiencing openness in learning is being assessed where the participants expressed that the open-ended mathematics questions were a form of tests for them. The second way of creativity experience is making decisions where the participants expressed that they were making choices and decisions while attempting the questions. The third way of experiencing creativity is exploring with freedom where the participants felt that they could explore space and freedom while doing questions.

This paper explores how teachers "see" the creativity experience of the participants, especially those who experience openness in learning by exploring with freedom. According to the participants, their creativity experience gave them the opportunity to think freely when they used many different methods to arrive at various answers in the open-ended mathematics questions. They realized they changed in the way they solved their questions because they willingly broke away from old methods while they explored alternative ways to arrive at their many answers to a question.

This paper investigates if teachers recognise the creativity experience of those who dared to explore with freedom.

\section{Method}

The 17 participants' written answers were assessed via Teachers' Consensual Assessment (TCA). This TCA was derived from Amabile's Consensual Assessment in creativity research (Amabile, 1982). In this study, the two experts are the experienced primary school teachers in Singapore. Both of them have been teaching mathematics in the local classrooms for more than 5 years and thus are very familiar with the subject of teaching and learning primary mathematics in Singapore. Written scripts here each contains the same 3 different types of open-ended mathematics questions.

In this study, the TCA reflected the natural setting of the primary school assessments in Singapore. The two teachers marked the same 17 participants' written scripts within the similar conditions given by the Ministry of Education (MOE) in Singapore. For instance, the researcher ensured that the discrepancies in marks were within those normally adhered to in the marking of PSLE papers in Singapore. The average of two teachers' total marks in this study (which include the method marks and the answer marks) is used to analyse their markings of the written scripts.

Each open-ended mathematics question was 5 marks with 4 marks awarded to method marks and 1 mark awarded for the correct answer. The participants were usually exposed to closed problems which had well-structured data, clearly formulated methods of arriving at one answer (Foong, 2000; 2002). Open-ended mathematics problem questions are illstructured with unclear formulated tasks and often reflect realworld problems. They also contain missing data or assumptions which may not have fixed procedures that arrived at a guaranteed correct solution (Foong, 2000; 2002). That is, open-ended mathematics questions can have many correct answers and multiple methods of getting to the correct answers.

In this study, the three different types of open-ended questions are (1) problem with missing data or hidden assumptions, (2) problem requiring an explanation of a concept, procedure, or error; and (3) problem-posing.

\section{A. Findings}

In the Teachers' Consensual Assessment (TCA), SPSS indicated the interrater-reliability of .7 and above for all three questions' method marks. For all three questions' answer marks, it was below .7 but could be explained by the only 1 mark attributed to each question. In the 17 written scripts' average total marks, two participants failed the paper, two participants obtained borderline marks, one participant obtained the perfect marks and 12 participants passed the paper.

\section{B. Discussions}

The researcher triangulated the children's creativity experience via phenomenographic analysis and the results from the Teachers' Consensual Assessment (TCA). Participants M7 and M16 both individually expressed more of this conception of exploring in freedom. But their written answers that should reflect their creativity experience via open-ended mathematics questions did not show the recognition by the two expert teachers. M7 obtained 54\% (borderline pass) in the paper while M16 got 33\% (fail) in the paper.

In the case of M7, the teachers did not understand his actual thoughts and cognitive processes when he toyed with new ideas and methods to answer the open-ended questions. He was also penalised for not showing the units correctly in the final answers. That is, he got the answer correct, but he did not write the units. In addition, no method marks were awarded to logical explanations in the mathematics as M7 did not show his accurate mental calculations. One of the teachers wrote on his script, "To get $5 / 5$, must have detailed calculation." Although M7 expressed more of his creativity experience by his willingness to explore with freedom in his 
written script and interview, the teachers did not appreciate his creativity experience. They did not like his methods and answers because he did not adhere to the norm of answering in a mathematics assignment. The following is an extract of M7's interview with the researcher:

Interviewer: O.K. So do you like to do these questions?

M7: $\quad$ Unlimited open ended questions yes.

Interviewer: You like it? Why?

M7: $\quad$ Because it lets your brain think.

Interviewer: Oh.... it lets your brain think. And you like to let your brain think?

M7: Yes.

Interviewer: Does it mean that in school, your brain doesn't think that much?

M7: $\quad$ Only when I do maths or problem sums.... quite boring then you must... like...squeeze your brain (taking more effort in solving problems with unlimited answers).

As for M16, he failed the written assignment because he explored the open-ended mathematics questions freely by his ability to "think out of the box" as shown in his methods in the three questions. When M16 encountered a new type of question, his methods indicated divergent thinking and convergent thinking which is good for creative problem solving. Teacher B examined M16's answers and remarked, "No clear solution nor explanation given." The teachers did not realise M16's exploring nature, they even penalised him for it. In this researcher's opinion, M16 appreciated his own creativity experience and knew what he wanted in his learning journey. Below is an extract that shows M16's thoughts on school:

Interviewer: Are you happy with whatever (that) is done in school right now?

M16: $\quad$ In a way yes but what I wish to actually add on is.. because the way thing... is like being stressed on in Primary 5s and Primary 6s are the exams and there's like you focus on the exams and nothing else and during like health education periods and other um..non...those subjects that...those noncore subjects they don't really teach you those. They just focus on the core subjects that are being tested in PSLE.

Interviewer: So in summary, can I say that you feel you would like to have more time to spend on even something that is like health education?

M16: $\quad$ Yah. A bit more of a variety of topics.

Interviewer: Okay. And not so ....

M16: $\quad$ Not too close confined to just school subjects.

\section{Conclusions and implications}

With the opportunity to hear the children's own creativity experience and triangulating them with their written works and feedback from the teachers, the conclusion here is that the primary schools teachers did not seem to appreciate children's creativity experience. The possible reason here is that teachers are not trained to recognise creativity in their children.

The implications here are two-folds if the Singapore classrooms want to foster creativity in schools. For the children, they should be given the time and space to explore learning in openness. For the teachers and schools, applicative implications such as teacher training to foster creativity and change the mindset of the children by allowing them to explore learning in openness. In addition, smaller class size is important to "get to know" students more.

Once teachers understand and appreciate creativity experience in children, it is a way to foster creativity in children in schools.

\section{References}

Amabile, T. M. (1982). Social psychology of creativity: A consensual assessment technique. Journal of Personality and Social Psychology, 43, 997-1013.

Antonietti, A. (2000). Enhancing creative analogies in primary school children. North American Journal of Psychology, 2(1), 75-84.

Cheng, V. M. Y. (2010). Tensions and dilemmas of teachers in creativity reform in a Chinese context. Thinking Skills and Creativity, 5, 120-137.

Dewey, J. (1938). Experience and education. NY: The Macmillan Co.

Foong, P. Y. (2000). Open-ended problems for higher-order thinking in mathematics. Teaching and Learning, 20(2), 49-57.

Foong, P. Y. (2002). The role of problems to enhance pedagogical practices in the Singapore mathematics classroom. The Mathematics Educator, 6(2), 15-31.

Hennessey, B.A., \& Amabile, T.A. (2010). Creativity. Annual Review of Psychology, 61, 569-598.

Marton, F. (1981). Phenomenography: Describing conceptions of the world around us. Instructional Science, 10, 177-200.

Marton, F. (1986). Phenomenography: A research approach to investigating different understandings of reality. Journal of Thought, 21(3), 28-49.

Marton, F., \& Booth, S. (1997). Learning and awareness. Mahwah, NJ: Lawrence Erlbaum Associates.

Rogers, C. (1961). On becoming a person: A therapist's view of psychotherapy. London: Constable.

United Nations General Assembly. (1989). The convention on the rights of the child: Adopted by the general assembly of the United Nations, 20 November $1989 . \quad$ Retrieved from http://www.un.org/documents/ga/res/44/a44r025.htm 